\section{SAT0509 BODY MASS INDEX AND DISEASE ACTIVITY IN PORTUGUESE AND BRAZILIAN JUVENILE IDIOPATHIC ARTHRITIS PATIENTS: RESULTS FROM RHEUMATIC DISEASES PORTUGUESE REGISTER - REUMA.PT}

Agna Neto $^{1,2}$, Ana Filipa Mourão $0^{1,2}$, Filipa Oliveira-Ramos ${ }^{3,4}$, José Melo Gomes ${ }^{5,6}$, Maria Jose Santos ${ }^{7}$, Raquel Campanilho-Marques ${ }^{3,4}$, Daniela Piotto ${ }^{8}$, Clovis Artur Silva ${ }^{8}$, Paula Estanqueiro ${ }^{9}$, Joao Eurico Fonseca ${ }^{3,4}$, Maria T. Tererri ${ }^{8}$, Helena Canhão ${ }^{10} .{ }^{1}$ Rheumatology, CHLO, Lisbon, Portugal; ${ }^{2}$ CEDOC, NOVA Medical School, Lisbon, Portugal; ${ }^{3}$ Rheumatology and Metabolic Bone Diseases, CHLN, Lisbon, Portugal; ${ }^{4}$ Rheumatology Research Unit, IMM, Centro Académico de Medicina de Lisboa, Lisbon, Portugal; ${ }^{5}$ Instituto Português de Reumatologia, Lisbon, Portugal; ${ }^{6}$ Clínica Dr. Melo Gomes, Lisbon, Portugal; ${ }^{7}$ Rheumatology, Hospital Garcia de Orta, Lisbon, Portugal; ${ }^{8}$ Pediatric Rheumatology Unit, Universidade Federal de São Paulo, São Paulo, Brazil; ${ }^{9}$ Pediatrics, Hospital Pediátrico Carmona da Mota, Coimbra, Portugal; ${ }^{10}$ CEDOC, EpiDoC Unit, NOVA Medical School, Lisbon, Portugal

Background: The influence of body mass index (BMI) on Juvenile Idiopathic Arthritis (JIA) disease activity is poorly understood. In adults with Rheumatoid Arthritis, obesity has been associated with higher disease activity, while in JIA patients, a previous study has failed to find any association.

Objectives: To investigate the relationship between BMI and JIA disease activity.

Methods: This is an international, multicenter, observational, cross-sectional study. JIA patients (according to ILAR criteria) aged $\leq 18$ years, registered at Reuma.pt in Portugal and Brazil were included. Data was analysed upon records from the first registered visit. Age- and sex-specific BMl percentiles $(P)$ were calculated based on WHO growth standard charts and categorized into underweight $(P<3)$, normal weight $(3 \leq P \leq 85)$, overweight $(85<P \leq 97)$ and obesity $(P>97)$. Disease activity was assessed by Juvenile Arthritis Disease Activity Score (JADAS-27). Univariate linear regression was used to examine the association of JADAS-27 with BMI categories. Two multivariate regression models were performed a) adjusting for age, gender, race, country, disease duration and JIA category (model 1); b) adjusting for those covariates plus use of DMARDs (model 2).

Results: 255 patients included, mean age 10.1 \pm 4.7 years, mean disease duration $6.3 \pm 4.9$ years; $62 \%$ female; $85 \%$ Caucasian. Thirty-two percent were persistent oligoarticular, $9 \%$ extended oligoarticular, 34\% polyarticular $\mathrm{RF}+, 6 \%$ systemic, $13 \%$ enthesitis-related arthritis, $5 \%$ psoriatic arthritis and $1 \%$ undifferentiated arthritis. The prevalence of underweight, normal weight, overweight and obesity was $7.5 \%, 65.9 \%, 15.7 \%$ and $11 \%$, respectively. In the univariate linear regression, underweight was significantly associated with higher JADAS-27, compared to normal weight $(B=-$ 9.563, $p<0.001)$, overweight $(B=-10.661, p<0.001)$ and obesity $(B=-7.422$, $p=0.004)$. Lower age $(B=-0.299, p=0.012)$, shorter disease duration $(B=-$ 0.396, $\mathrm{p}=0.001)$, black race $(\mathrm{B}=6.852, \mathrm{p}=0.033), \quad \mathrm{FF}+$ polyarthritis $(B=7.101, p<0.001)$, living in Brazil $(B=5.357, p=0.002)$ and the absence of DMARD therapy $(B=4.831, p<0.001)$ were also associated with higher JADAS-27.

In the model 1 of multivariate analysis, the same variables, except the country, remained significantly associated with higher disease activity. When DMARD therapy was added to the model (model 2), RF+ polyarthritis $(B=4.447, p=0.001)$ and living in Brazil $(B=4.728, p=0.013)$ were associated with higher JADAS-27. Patients with normal weight $(B=-9.964$, $p<0.001)$, overweight $(B=-10.316, \quad p<0.001)$ and obesity $(B=-9.502$, $p=0.001$ ) had significantly lower activity disease, compared to underweight patients, as well as those under DMARD therapy $(B=-4.858, p<0.001)$. Conclusion: Despite the lack of adjustment for corticosteroids use, there seems to be an independent association between underweight and higher

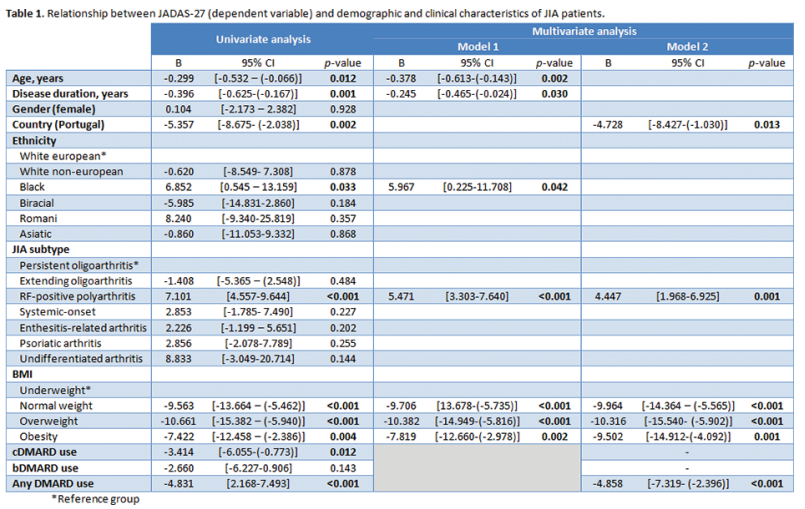

disease activity in JIA patients. Importantly, these results suggest that active disease can impair child's weight gain. Further studies are needed to confirm these findings and understand the underlying mechanisms of this association.

Disclosure of Interests: None declared

DOI: 10.1136/annrheumdis-2019-eular.6349

\section{SAT0510 NON-BACTERIAL OSTEITIS IN CHILDREN: PROGNOSTIC FACTORS}

Nuria Heredia Torres ${ }^{1}$, Esmeralda Núñez Cuadros ${ }^{2,3}$, Rocío Galindo Zavala ${ }^{3}$ Gisela Diaz-Cordobes ${ }^{4}$, Laura Martín Pedraz ${ }^{3}$, Antonio Urda Cardona ${ }^{1} .{ }^{1}$ Hospital Regional Universitario de Málaga, Pediatrics, Málaga, Spain; ${ }^{2}$ Malaga, Paediatric Rheumatology Unit, Málaga, Spain; ${ }^{3}$ Hospital Regional Universitario de Málaga, Pediatric Rheumatology Unit, Málaga, Spain; ${ }^{4}$ Hospital Regional Universitario de Málaga, Rheumatology, Málaga, Spain

Background: The incidence of non-bacterial osteitis (NBO), a rare autoinflammatory disease in childhood, has increased over the past few years. Early diagnosis and treatment, as well as an adequate follow-up, are necessary to prevent sequelae and complications. However, prognostic factors of the disease are unknown.

Objectives: To establish the prognostic factors of NBO

Methods: A retrospective study of NBO, according to Jansson criteria, in children ( $<14$ years) at a tertiary hospital from 2009 to 2018. Descriptive statistics were performed to examine clinical features, diagnoses, treatments and progress of the disease. Furthermore, bivariate analysis was performed in order to investigate factors involved in the remission of the disease (with/out treatment), the number of relapses and sequelae. We considered $p<0,1$ as significance level due to the small sample size.

Results: We reviewed 15 cases. Table shows the descriptive data. The likelihood of remission was found to be associated with the presence of X-ray findings apart from sclerosis/lysis, ( $80 \%$ vs $40 \%, p$ 0.07), a high white blood cell count $(\mathrm{mm} 3)$ (11988.7 \pm 3004.9 vs $8915.7 \pm 3310.3$, p $0.08)$ and $\operatorname{ESR}(\mathrm{mm})(58.3 \pm 36.3$ vs $26.8 \pm 17.4, p 0.05)$ at diagnosis

Table. Descriptive analysis

\begin{tabular}{|c|c|}
\hline \multicolumn{2}{|c|}{ EPIDEMIOLOGIC DATA } \\
\hline Sex (female), n (\%) & $13(86.7)$ \\
\hline Age (years), mean ( $\pm S D$ ) & $9,5( \pm 1,7)$ \\
\hline Delayed diagnosis (months), median (IQR) & $3(2-6)$ \\
\hline Clinical presentation, $\mathbf{n}(\%)$ & \\
\hline Pain & $15(100)$ \\
\hline Limited movemen & $13(86,7)$ \\
\hline Swelling & $9(60)$ \\
\hline No. of lesions, median (IQR) & $2(1-5)$ \\
\hline Bone lesion sites ( $n=43), n(\%)$ & \\
\hline Clavicles & $8(53,3)$ \\
\hline Hip & $7(46,7)$ \\
\hline Others & $20(26,7)$ \\
\hline \multicolumn{2}{|c|}{ BIOLOGICAL TESTS } \\
\hline Blood test & \\
\hline White blood cells $(\mathrm{mm} 3)$, mean $( \pm S D)$ & $10554,7( \pm 3424,8)$ \\
\hline CRP (mg/L) at diagnosis, median (IQR) & $9,2(4,9-18,1)$ \\
\hline ESR $(\mathrm{mm})$ at diagnosis, mean $( \pm \mathrm{SD})$ & $43,7( \pm 32,5)$ \\
\hline MRI (n=14), findings, $n(\%)$ & \\
\hline Edema & $12(85,7)$ \\
\hline Lysis and/or cortical disruption & $5(35,7)$ \\
\hline Periosteal reaction & $3(21,4)$ \\
\hline Bone biopsy ( $n=12$ ); histopathology, $n(\%)$ & \\
\hline Fibrosis & $9(75)$ \\
\hline Inflammation & $8(66,7)$ \\
\hline \multicolumn{2}{|c|}{ TREATMENT } \\
\hline $\begin{array}{l}\text { Antibiotics, } \boldsymbol{n}(\%) \\
\text { Duration (days), mean }( \pm S D)\end{array}$ & $\begin{array}{l}8(53,3) \\
50,5( \pm 15,9)\end{array}$ \\
\hline NSAIDs, $\mathrm{n}(\%)$ & $14(93,3)$ \\
\hline Duration (days), median (IQR) & $72(19,5-219,5)$ \\
\hline Corticoids, $\mathbf{n}(\%)$ & $9(60)$ \\
\hline Duration (days), median (IQR) & $110(60-195)$ \\
\hline Methotrexate, $n(\%)$ & $2(13,3)$ \\
\hline Duration (days), median (IQR) & $547,5(365-547,5)$ \\
\hline Pamidronate, $\mathrm{n}(\%)$ & $8(53,3)$ \\
\hline No. of cycles, mean ( $\pm \mathrm{SD}$ ) & $7,8( \pm 6,9)$ \\
\hline Zoledronate, $n(\%)$ & $4(26,7)$ \\
\hline No. of cycles, median (IQR) & $3(2,3-3)$ \\
\hline TNF inhibitors, $n(\%)$ & $3(20)$ \\
\hline Duration (days), median (IQR) & $880(300-880)$ \\
\hline \multicolumn{2}{|c|}{ OUTCOME } \\
\hline No. of relapses, median (IQR) & $2(0-6)$ \\
\hline Follow-up time (years), mean ( \pm SD) & $4,5( \pm 2,8)$ \\
\hline Current status, n (\%) & \\
\hline Remission without treatment & $8(53.3)$ \\
\hline Remission with treatment & $7(46.7)$ \\
\hline Sequelae, $n(\%)$ & \\
\hline Localized deformation & $2(13.3)$ \\
\hline
\end{tabular}

